\title{
Episodic Nonlinearity in Leading Global Currencies
}

Anastasios G. Malliaris

Loyola University Chicago, tmallia@luc.edu

Apostolos Serletis

University of Calgary

Melvin J. Hinich

The University of Texas at Austin

Periklis Gogas

Democritus University

Follow this and additional works at: https://ecommons.luc.edu/business_facpubs

Part of the Business Commons

\section{Author Manuscript}

This is a pre-publication author manuscript of the final, published article.

\section{Recommended Citation}

Malliaris, Anastasios G.; Serletis, Apostolos; Hinich, Melvin J.; and Gogas, Periklis. Episodic Nonlinearity in Leading Global Currencies. Open Economies Review, 23, 2: 337-357, 2012. Retrieved from Loyola eCommons, School of Business: Faculty Publications and Other Works, http://dx.doi.org/10.1007/ s11079-010-9194-9

This Article is brought to you for free and open access by the Faculty Publications and Other Works by Department at Loyola eCommons. It has been accepted for inclusion in School of Business: Faculty Publications and Other Works by an authorized administrator of Loyola eCommons. For more information, please contact ecommons@luc.edu.

\section{(c) $($ †) $\ominus$}

This work is licensed under a Creative Commons Attribution-Noncommercial-No Derivative Works 3.0 License. (C) Springer International Publishing AG 2012 


\title{
Episodic Nonlinearity in Leading Global Currencies*
}

\author{
Apostolos Serletis ${ }^{\dagger}$ \\ Department of Economics \\ University of Calgary, Canada \\ Anastasios G. Malliaris \\ Department of Economics \\ Loyola University of Chicago, U.S. \\ Melvin J. Hinich \\ Department of Government and Economics \\ The University of Texas at Austin, U.S. \\ and \\ Periklis Gogas \\ Department of International Economic Relations and Development \\ Democritus University, Greece
}

June 8, 2010

\footnotetext{
${ }^{*}$ We are thankful to Joko Mulyadi for valuable research assistance in collecting the data.

${ }^{\dagger}$ Corresponding author. Phone: (403) 220-4092; Fax: (403) 282-5262; E-mail: Serletis@ucalgary.ca; Web: http://econ.ucalgary.ca/serletis.htm.
} 


\begin{abstract}
We perform non-linearity tests using daily data for leading currencies that include the Australian dollar, British pound, Brazilian real, Canadian dollar, euro, Japanese yen, Mexican peso, and the Swiss franc to resolve the issue of whether these currencies are driven by fundamentals or exogenous shocks to the global economy. In particular, we use a new method of testing for linear and nonlinear lead/lag relationships between time series, introduced by Brooks and Hinich (1999), based on the concepts of cross-correlation and crossbicorrelation. Our evidence points to a relatively rare episodic nonlinearity within and across foreign exchange rates. We also test the validity of specifying ARCH-type error structures for foreign exchange rates. In doing so, we estimate Bollerslev's (1986) generalized ARCH (GARCH) model and Nelson's (1988) exponential GARCH (EGARCH) model, using a variety of error densities [including the normal, the Student- $t$ distribution, and the Generalized Error Distribution (GED)] and a comprehensive set of diagnostic checks. We apply the Brooks and Hinich (1999) nonlinearity test to the standardized residuals of the optimal GARCH/EGARCH model for each exchange rate series and show that the nonlinearity in the exchange rates is not due to ARCH-type effects. This result has important implications for the interpretation of the recent voluminous literature which attempts to model financial asset returns using this family of models.
\end{abstract}

JEL classification: C22, C45, D40, G10, Q40.

Keywords: Global financial markets; Currencies; Episodic nonlinearity; Conditional heteroskedasticity. 


\section{Introduction}

For many centuries, national economies have been linked to one another financially primarily because of trade. The importing nation received goods and paid in some pre-agreed currency. Currency trading predates both bond and stock trading as a financial innovation. However, there is very little doubt that during the past 50 years globalization grew at a remarkable pace and with it, currency trading. Today, the daily volume of currency transactions in currency futures, forwards, swaps and options dominates all other types of trading volumes. This volume is driven by globalization that includes both trade and foreign direct investments, by portfolio diversification, and by hedging and speculation, among other factors.

After a rapid bibliographic review of the importance of global currencies in the next three sections we use daily data to perform state-of-the-art statistical tests to identify economic and statistical characteristics of several key currencies. In particular, we use daily exchange rates (per United States dollar) on the Australian dollar, British pound, Brazilian real, Canadian dollar, euro, Japanese yen, Mexican peso, and the Swiss franc, over the period from January 3, 2000 to June 2, 2009 (a total of 2,492 observations). In section 7, we follow Brooks and Hinich (1999) and draw two somewhat disparate areas of research into nonlinearity and multivariate time series analysis together, using a test for nonlinearity, proposed by Brooks and Hinich (1999), which allows for cross-correlations and cross-bicorrelations between pairs of series. These tests can be viewed as natural multivariate extensions of Hinich's (1996) portmanteau bicorrelation and whiteness statistics which search for nonlinear cofeatures between time series. Our evidence points to a relatively rare episodic nonlinearity within and across exchange rate series, having important implications for forecasting these series.

Recent leading-edge research has applied Engle's (1982) autoregressive conditional heteroscedastic (ARCH) model, Bollerslev's (1986) generalized ARCH (GARCH) model, and Nelson's (1988) exponential GARCH (EGARCH) model to capture nonlinearities and to estimate time-varying variances in foreign exchange rates [see, for example, Hsieh (1989) and Baillie and Bollerslev (1989)]. In section 8, we follow these recent advances in the financial econometrics literature and conduct a thorough investigation to properly identify the type of heteroscedasticity in the data generation process of the eight exchange rate series. This is of major importance in forecasting, since these models allow the conditional variance to depend on elements of the information set. In doing so, we use a variety of error densities, including the normal, the Student- $t$ distribution, and the Generalized Error Distribution (GED), as well as a comprehensive set of diagnostic checks. We also apply the Brooks and Hinich (1999) nonlinearity test to the standardized residuals of the optimal ARCH-type model for each exchange rate series and show that the nonlinearity in the exchange rates is not due to ARCH-type effects. This result has important implications for the interpretation of the recent voluminous literature which attempts to model financial asset returns using this family of models.

The final section concludes the paper with a brief discussion of the implications of our 
empirical results.

\section{Globalization}

Globalization is an extension of labor specialization beyond national borders and it is important to understand the international economic developments of the last fifty years. With a deepening of specialization, a growing population and improved attitudes toward taking risks over a widening area, production has become increasingly international. The technological advances of recent decades have increased the effects of globalization on economic growth and during the last decades policy makers have been trying to better understand global and technological changes that seemed to have changed world economic development. Changes in information and communication technologies, for example, have accelerated the processing and transmission of data and ideas to a level far beyond our capabilities of a decade or two ago. Real-time information, by eliminating much human intervention, has significantly reduced errors in all forms of recordkeeping and lead times on purchases. These changes have had positive effects on the economic well-being for most of the economic participants, but if globalization is to sustain the necessary public support we need also to consider an equitable distribution of global benefits among participating nations. Fortunately, global trade has long been viewed as a positive sum game that benefits all participants. Although such benefits are clearly positive they need not be equal.

The dynamics of globalization include the lowering of tariffs and various trade barriers, deregulation, increased innovation and competition, the emergence of multinational firms, increased global trade and direct foreign investments, and a faster pace in global GDP growth than in earlier decades. As a result, domestic economies are increasingly exposed to international competition. Production of traded goods has increased in economies with large, low-wage labor forces and as a consequence, significant additions to world production and trade have put downward pressure on domestic and global prices. This trend of declining prices all over the world has been an important factor in the decrease of world economic volatility. To many people, the combination of increasing globalization and monetary policy has become increasingly effective in achieving the goal of price stability. This view, called the Great Moderation, dominated economic thinking during 1990-2006, but the global financial crisis of 2007-2009 has challenged this paradigm. The current thinking suggests that globalization contributed to stable and low prices that encouraged various central banks to maintain low interest rates, since there were no obvious risks of inflation and such an easy monetary policy on a global scale contributed to the emergence of financial bubbles both in global stock markets and housing prices. Considering that so much of our recent experience with globalization has little precedent, we cannot fully determine how long the current globalization dynamic will last. We have little evidence that economic forces that are fostering international specialization, and hence cross-border trade and increasing dispersion of 
current account balances, are as yet diminishing.

The increasing globalization of the post-war world was supported at its beginnings by the judgment that burgeoning prewar protectionism was among the primary causes of the depth of the Great Depression of the 1930s. As a consequence, trade barriers began to fall after the war. Globalization was enhanced further when the inflation-ridden 1970s provoked rethinking of the philosophy of economic policy, the roots of which were still planted in the Depression era. Globalization has expanded markedly in recent decades. Not only has the ratio of international trade in goods and services to world GDP risen inexorably over the past half-century, but a related measure, the extend to which savers reach beyond their national borders to invest in foreign assets, has also risen. During some time after World War II, countries were used to invest most of their domestic savings in domestic capital assets without considering the potential for superior risk-adjusted returns if they were to invest abroad. In the beginning of the 1990s, this bias to invest in domestic capital assets started do decrease and countries started to invest their current account balances in different places. Thus, this expanding globalization enabled the United States to finance and, hence, incur so a large current account deficit. As a result of these capital flows, the ratio of foreign net claims against U.S. residents to U.S. annual GDP has risen to approximately one-fourth. While some other countries are far more in debt to foreigners, at least relative to their GDPs, they do not face the scale of international financing that the United States requires.

We may not be able to usefully determine at what point foreign accumulation of net claims on the United States will slow or even reverse, but up until recently it was postulated that the greater the degree of international flexibility, the less the risk of a crisis. Obviously we now know that globalization during the last three years has caused serious financial imbalances, in particular in terms of emerging nations such as China, financing along with advanced economies such as the European Union, Japan, and England, the United States twin deficits of the federal budget and the balance of payments. In a world economy that is flexible, as debt projections rise, product and equity prices, interest rates, and exchange rates presumably would change to reestablish global balance. However, the penchant of humans for quirky, often irrational, behaviors gets in the way of this conclusion as recent history has demonstrated. A discontinuity in valuation judgments, often the cause building a bubble, may quickly reverse and contribute to bursting such bubbles. Such developments can occasionally destabilize even the most liquid and flexible of markets as was witnessed during the current global financial crisis, in particular during the month of September 2008.

\section{Portfolio Diversification}

Increased financial globalization has offered important opportunities for portfolio diversification. There is a wide spectrum of financial risks that include firm specific risks, industry wide risks, and country risks. Several macroeconomic policies such as monetary policy, fiscal 
policy, and the level of regulation are included in country risks, among several other factors. The growth in the size and complexity of international financial markets has been one of the most striking aspects of the world economy over the last decade. Lane and Milesi-Ferretti (2001, 2006) document the increase in gross holdings of cross-country bonds and equities for a large group of countries. They describe this as a process of financial globalization. Economists and policy makers have speculated on the implications of financial globalization for the design of monetary policy. Most central banks now either explicitly or implicitly follow a policy of inflation targeting. Under this policy, price stability, appropriately defined, is the principal goal of monetary policy.

Devereux and Sutherland (2007) show that financial globalization does not affect the fundamental aims of monetary policy. Although their model produces an international financial structure where countries are holding large offsetting gross nominal asset positions, so that exchange rate movements can generate substantial 'valuation effects,' the presence of these effects does not directly change the optimal monetary rule. Because portfolios are chosen optimally, the wealth redistribution arising from exchange-rate-induced valuation effects represents the workings of an efficient international financial structure. However, Devereux and Sutherland (2007) argue that the effects of monetary policy on other variables may be very different in a model with endogenous portfolio choice than in the standard analysis. Because the monetary rule leads to changes in the structure of international portfolios, the effects of monetary policy may be the opposite of what traditional reasoning would imply. For instance, a policy putting more weight on price stability may increase rather than reduce exchange rate volatility and the volatility of international capital flows.

Over the period from 1975 to 2005, the United States dollar and the euro and Swiss franc have moved against world equity markets. Thus, these currencies should be attractive to riskminimizing global equity investors despite their low average returns. The risk-minimizing currency strategy for a global bond investor is close to a full currency hedge, with a modest long position in the U.S. dollar. Many investors hold indirect positions in foreign currency when they buy foreign equities or bonds without hedging the currency exposure implied by the foreign asset holding. Such investors receive the foreign-currency excess return on their foreign assets, plus the return on foreign currency. Campbell et al. (2009) considered an equity investor who chooses fixed currency weights to minimize the unconditional variance of her portfolio. Such an investor wishes to hold currencies that are negatively correlated with equities. Their first novel result is that at one extreme, the Australian dollar and the Canadian dollar are positively correlated with local-currency returns on equity markets around the world, including their own domestic markets. At the other extreme, the euro and the Swiss franc are negatively correlated with world stock returns and their own domestic stock returns. The Japanese yen, the British pound, and the U.S. dollar fall in the middle, with the yen and the pound more similar to the Australian and Canadian dollars, and the U.S. dollar more similar to the euro and the Swiss franc. 


\section{Hedging and Speculation}

When considering currencies in pairs, Campbell et al. (2009) found that risk-minimizing equity investors should short those currencies that are more positively correlated with equity returns and should hold long positions in those currencies that are more negatively correlated with returns. When considering all seven currencies as a group, they found that optimal currency positions tend to be long in the U.S. dollar, the Swiss franc, and the euro, and short in the other currencies. A long position in the U.S.-Canadian exchange rate is a particularly effective hedge against equity risk. Campbell et al. (2009) achieved the second novel result when they considered the risk-minimization problem of global bond investors rather than global equity investors. They found that most currency returns are almost uncorrelated with bond returns and thus risk-minimizing bond investors should fully currency-hedge their international bond positions. The U.S. dollar is an exception to the general pattern in that it tends to appreciate when bond prices fall (that is, when interest rates rise) around the world. This generates a modest demand for U.S. dollars by risk-minimizing bond investors.

The third novel result was obtained after Campbell et al. (2009) analyzed the historical average returns on currency pairs. They found that high-beta pairs have delivered higher average returns. However the historical reward for taking equity beta risk in currencies has been quite modest, and much smaller than the historical average excess return on a global stock index. The fourth novel result is that increases in interest rates have only modest effects on currency-equity covariances. Over the full sample period, and particularly the first half of the sample, increases in interest rate differentials are, if anything, associated with decreases in these covariances. This implies that risk-minimizing equity investors should tilt their portfolios towards currencies that have temporarily high interest rates, amplifying the speculative 'carry trade' demands for such currencies rather than offsetting them.

\section{$5 \quad$ Hypotheses}

The above brief discussion leads us to the conclusion that certain global currencies have received great significance over the past few decades. When we also consider the creation of the euro, this significance becomes even greater, since several important national currencies such as the German marc, the French franc, the Italian lira, and several others were replaced by the euro. This global significance translates into a search for the pricing of these currencies. The challenge becomes even greater since currencies are priced one in terms of another. One may view the issue of pricing currencies as a comparison of all economic and financial fundamentals between two nations.

When pricing equities, economists have observed that returns have exhibited strong, short, and medium-term serial correlation. The phenomenon of persistent performance over time has challenged the traditional random walk assumption for stock returns. The 
basic idea is that a single normal distribution is insufficient to describe the observed stock returns, evidenced by fat tails, skewness, and excess kurtosis. The classical intertemporal capital asset pricing model (CAPM) model of Merton (1980) indicates that risk premiums are positively related to market volatility. However, other researchers have found different results. A large stock price drop is usually associated with a concurrent increase in volatility, which makes equity returns and volatility negatively correlated. This market phenomenon has led to two academics explanations. One is the leverage effect and the other one is the volatility feedback effect.

The leverage effect argues that a stock price drop increases the debt to equity ratio, which makes the stock riskier and raises the equity risk premium. That is, the leverage effect relates realized stock returns to future returns volatility. The volatility feedback effect, which reverses the direction of causality, assumes that volatility is incorporated in stock prices and carried over to future returns; a positive volatility shock increases the future required return on equity and, therefore, stock prices are expected to fall simultaneously. Conclusions drawn from both of these academic thoughts are not satisfactory, due to insignificant relations implied in their empirical work and researchers using the same model were able to find competing results.

Instead of pricing currencies, in this paper we study the time series behavior of leading currency relative prices. Our main hypothesis is that perfect randomness in price changes for all currencies does not hold. If price changes are not random but follow nonlinear deterministic patterns such information may allow economists to better evaluate the overall impact of leading currencies in the global economy. We use recent state-of-the-art developments in the financial econometrics literature to uncover the structure of currency prices for several leading currencies. For more details regarding the presence of non-linear determinism in financial markets, see Mandelbrot and Hudson (2004).

\section{The Data}

We use daily exchange rates (per United States dollar), provided by www.barchart.com, on the Australian dollar, British pound, Brazilian real, Canadian dollar, euro, Japanese yen, Mexican peso, and the Swiss franc. The sample period is from January 3, 2000 to June 2, 2009 (a total of 2,492 observations). Figure 1 plots U.S. dollar prices of each of the eight currencies. A rise in these plots indicates a strengthening of the currency (a weakening of the U.S. dollar). In Figure 2, we plot first logarithmic differences of the nominal exchange rates and in Figure 3 we show the frequency distributions of the first logged differences in the form of histograms. Summary statistics (not reported here) indicate that the skewness parameters are close to zero for all series, but that the kurtosis parameters are all greater than 3 , suggesting peaked (leptokurtic) distributions relative to the normal distribution, consistent with the evidence in Figure 3. In fact, the Jarque and Bera (1980) test statistic, distributed 
as a $x^{2}(2)$ distribution under the null hypothesis of normality, leads to the rejection of the null hypothesis of a normal distribution with $p<.0001$ for each exchange rate series.

The first step in conducting nonlinear analysis is to test for stochastic trends (unit roots) in the autoregressive representation of each individual time series. In doing so, we use three alternative unit root testing procedures to deal with anomalies that arise when the data are not very informative about whether or not there is a unit root. In particular, we use the augmented Weighted Symmetric (WS) unit root test [see Pantula et al. (1994)], the augmented Dickey-Fuller (ADF) test [see Dickey and Fuller (1981)], and the nonparametric, $Z\left(t_{\widehat{\alpha}}\right)$, test of Phillips (1987) and Phillips and Perron (1988). For the WS and ADF tests, the optimal lag length was taken to be the order selected by the Akaike information criterion (AIC) plus 2 - see Pantula et al. (1994) for details regarding the advantages of this rule for choosing the number of augmenting lags. The $Z\left(t_{\widehat{\alpha}}\right)$ test is done with the same Dickey-Fuller regression variables, using no augmenting lags. Based on the $p$-values for the WS, ADF, and $Z\left(t_{\widehat{\alpha}}\right)$ test statistics (not reported here, but available upon request), the null hypothesis of a unit root in the first logged differences can be rejected for each exchange rate series. Thus, we conclude that all the first logged differenced exchange rate series are stationary.

\section{Testing for Nonlinearity}

We test for nonlinearity in the stationary, first logged differenced exchange rate series using the windowed test of Brooks and Hinich (1999). Let us consider a sample of length $N$ of two jointly covariance stationary time series $\left\{x\left(t_{k}\right)\right\}$ and $\left\{y\left(t_{k}\right)\right\}$, which have been standardized to have a sample mean of zero and a sample variance of one, by subtracting the sample mean and dividing by the sample standard deviation in each case. Since we are working with small subsamples of the whole series, stationarity is not a stringent assumption. The null hypothesis for the test is that the two series are independent pure white noise processes, against an alternative that some cross-bicovariances between $\left\{x\left(t_{k}\right)\right\}$ and $\left\{y\left(t_{k}\right)\right\}$, denoted $C_{x x y}(r, s)$

$$
C_{x x y}(r, s)=E\left[x\left(t_{k}\right) x\left(t_{k}+r\right) y\left(t_{k}+s\right)\right],
$$

are nonzero. As a consequence of the invariance of $E\left[x\left(t_{1}\right) x\left(t_{2}\right) y\left(t_{3}\right)\right]$ to permutations of $\left(t_{1}, t_{2}\right)$, stationarity implies that the expected value is a function of two lags and that $C_{x x y}(-r, s)=C_{x x y}(r, s)$. If the maximum lag used is $L<N$, then the principal domain for the bicovariances is the rectangle $\{1 \leq r \leq L,-L \leq s \leq L\}$.

Under the null hypothesis that $\left\{x\left(t_{k}\right)\right\}$ and $\left\{y\left(t_{k}\right)\right\}$ are pure white noise, then $C_{x x y}(r, s)=$ $0 \forall r, s$ except when $r=s=0$. This is also true for the less restrictive case when the two processes are merely uncorrelated, but the theorem mentioned below to show that the test statistic is asymptotically normal requires independence between the two series. If there is second or third order lagged dependence between the two series, then $C_{x x y}(r, s) \neq 0$ for at least one $r$ value or one pair of $r$ and $s$ values, respectively. The following statistic gives the 
$r$ sample $x x y$ cross-bicorrelation

$$
C_{x x y}(r, s)=\frac{1}{N-m} \sum_{t=1}^{N-m} x\left(t_{k}\right) x\left(t_{k}+r\right) y\left(t_{k}+s\right)
$$

where $m=\max (r, s)$.

The cross-bicorrelation in equation (1) can be viewed as a correlation between the current value of one series and the value of previous cross-bicorrelations between the two series. Note that the summation in the second-order case (??) does not include contemporaneous terms, and is conducted on the residuals of an autoregressive fit to filter out the univariate autocorrelation structure so that contemporaneous correlations will not cause rejections. For the third-order test, we estimate the test on the residuals of a bivariate vector autoregressive model containing a contemporaneous term in one of the equations. The motivation for this prewhitening step is to remove any traces of linear correlation or cross-correlation so that any remaining dependence between the series must be of a nonlinear form. It can then be shown that

$$
\begin{aligned}
& E\left[C_{x x y}(r, s)\right]=0, \\
& E\left[C_{x x y}^{2}(r, s)\right]=\frac{1}{N-m}
\end{aligned}
$$

under the null hypothesis. Let $L=N^{c}$ where $0<c<0.5-$ in this application we use $c=0.25$, although the results and the null distribution of the test are not very sensitive to changes in this parameter. The test statistics for nonzero cross-correlations and crossbicorrelations are given by

$$
H_{x y}(N)=\sum_{r=1}^{L}(N-r) C_{x y}^{2}(r)
$$

and

$$
H_{x x y}(N)=\sum_{s=-L}^{L}, \sum_{r=1}^{L}(N-m) C_{x x y}^{2}(r, s), \quad\left({ }^{\prime}-s \neq-1,1,0\right),
$$

respectively. These tests are joint or composite tests for cross-correlations and crossbicorrelations (in a similar vein to the Ljung-Box $Q^{*}$ test for autocorrelation), where the number of correlations tested for is $L$ and the number of cross-bicorrelations tested for is $L(2 L-1)$. According to Hinich (1996, Theorem 1), $H_{x y}$ and $H_{x x y}$ are asymptotically $\chi^{2}$ with $L$ and $L(2 L-1)$ degrees of freedom, respectively, as $N \rightarrow \infty$. Here, however, we bootstrap the test statistics and thus we are not using the asymptotic variance. The Txy program that we used is available at Hinich's webpage at www.gov.utexas.edu/hinich. 
Each exchange rate return series was divided into non-overlapping frames of length 100 yielding 24 full frames; the last 92 days were discarded. The bandwidth parameter was 0.35 yielding five lags for the bicorrelations. Thus the number of bicorrelations is 55 . Twelve pairs of exchange rates were selected from the 28 possible pairs in order to simplify the exposition. Table 1 presents the $p$-value results for two auto bicorrelation portmanteau tests and the two cross bicorrelation tests. Only $p$-values less than or equal to 0.05 are reported. The empty cells in the table indicate that those $p$-values were greater than 0.05 . There was at least one frame with highly statistically significant $p$-values for either an auto bicorrelation test or a cross bicorrelation test. The Brazilian real-Canadian dollar had the most significant frames - seven. The euro-yen and the pound-yen had five significant frames. The results show that there are episodic nonlinear events in 100 day frames where the nonlinearity is either within the exchange rate time series or between pairs or both. Table 1 also provides the dates when these episodic nonlinearities occurred, which is potentially useful for our future investigation into the causes of this detected episodic behavior.

These results demonstrate that the underlying nonlinear generating process for the exchange rate series is episodic in nature in which the nonlinear dependence appears only infrequently. Another pertinent feature is the transient nature of these dependencies, in which some correlations appear highly significant, but then quickly disappear, or become too weak to be detected in subsequent windows. This provides a plausible explanation for the failure of researchers to exploit the detected nonlinearity in making improved point forecasts. In particular, though the presence of nonlinearity implies the potential of predictability, the dependency structures do not seem to be persistent enough to benefit from it. That is, these dependencies show up at random intervals for a brief period of time but then disappear again before they can be exploited.

\section{Modeling Heteroskedasticity}

Having concluded that the logged first differences of the exchange rates are stationary and exhibit episodic nonlinearity, in this section we model the conditional hereroskedasticity in these series. In doing so, we use the class of autoregressive conditional heteroskedasticity models, originally suggested by Engle (1982). This class of models relaxes the assumption of the classical linear regression model that the variance of the disturbance term is conditionally as well as unconditionally constant.

We start by estimating the best fitted autoregressive model for each series according to the following equation

$$
\Delta \ln z_{t}=\sum_{i=1}^{r} \phi_{i} \Delta \ln z_{t-i}+\sum_{k=1}^{5} d_{k} D_{k t}+\varepsilon_{t}
$$


where $D_{k t}$ are day of the week dummy variables, $r$ is the order of the autoregression, and $\phi$ and $d$ are unknown parameters to be estimated.

We first select a minimum autoregression order $r_{\min }$ for each series such that the models show no autocorrelation according to the $Q(36)$ test statistic. Then we use both the Schwartz Information Criterion (SIC) and the Akaike Information Criterion (AIC) to optimally determine the value of $r$ in equation (2), by estimating several models with $r=r_{\text {min }}$ to $r=25$. However, as the AIC tends to overparameterize the model while the SIC tends to select the true model as the sample size increases (and if the true model is included in the choices), we follow the SIC in selecting the optimal lag length of the autoregression, $r$. The results are reported in Table 2.

Both visual inspection and the use of the $Q(36)$ statistic for residual serial correlation (as seen in the last two columns of Table 3) suggest that the residuals of the autoregressive model with the order of the autoregression, $r$, chosen as above are not serially correlated. However, the $Q^{2}(36)$ statistic, which represents the $Q$-statistic for the squared residuals and is designed to pick nonlinearities and the presence of heteroskedasticity, is highly significant providing evidence for the presence of conditional heteroskedasticity in the error term. For this reason in order to capture the heteroskedasticity in the error term we estimate the autoregressive $\operatorname{AR}(r)$ model (2) for each series assuming that $\varepsilon_{t}$ is $I N\left(0, \sigma_{t}^{2}\right)$ with $\sigma_{t}^{2}$ following a $\operatorname{GARCH}(p, q)$ process as follows,

$$
\sigma_{t}^{2}=w_{0}+\sum_{i=1}^{q} \alpha_{i} \varepsilon_{t-i}^{2}+\sum_{j=1}^{p} \beta_{j} \sigma_{t-j}^{2}+\sum_{k=2}^{5} d_{k} D_{k t}
$$

or an $\operatorname{EGARCH}(\mathrm{p}, \mathrm{q})$ process as follows

$$
\log \left(\sigma_{t}^{2}\right)=w_{0}+\sum_{i=1}^{q}\left(\alpha_{i}\left|\frac{\varepsilon_{t-i}}{\sigma_{t-i}}\right|+\gamma_{i} \frac{\varepsilon_{t-i}}{\sigma_{t-i}}\right)+\sum_{j=1}^{p} \beta_{j} \log \left(\sigma_{t-j}^{2}\right)+\sum_{k=2}^{5} d_{k} D_{k t}
$$

see, for example, Bollerslev (1986) and Nelson (1991), respectively, for more details.

In both equations (3) and (4) above, $p, q \in[1,2]$ such that eight different conditional heteroskedasticity specifications are estimated for each series. The lagged values of the error term, $\varepsilon_{t-i}, i=1, \cdots, q$, in equations (3) and (4) represent news in the market about volatility in the previous period, while the lagged values of the conditional variance, $\sigma_{t-j}^{2}, j=1, \cdots, q$, are lagged forecasted variances. Thus, this period's variance prediction is formed as a weighted average of a long term average (the constant, $w_{0}$ ), the forecasted variance from previous periods, and information about volatility observed in earlier periods. This variance modeling is consistent with the volatility clustering observed in the returns of the eight series (see Figure 2).

In Table 4 we report the optimal model selected by each of the two criteria - the AIC and SIC. For reasons discussed earlier we again use the SIC to select the best model for 
each exchange rate series and according to this for all series a $\operatorname{GARCH}(1,1)$ is the best specification of the conditional variance with the exception of the Brazilian real where the $\operatorname{EGARCH}(1,1)$ is selected.

The models estimated and selected so far use the normal distribution as the density function for the error term. Now we explore different error distributions in an attempt to improve the fit of the models. In particular, in addition to the normal distribution we use the Student's $t$ distribution, used by Bollerslev (1987), and the generalized error distribution (GED), used by Nelson (1988) for each of the eight exchange rate series. The Student's $t$ distribution is given by

$$
f(z)=\theta^{-.5} \pi^{-.5} \Gamma\left(\frac{\theta+1}{2}\right) \Gamma\left(\frac{\theta}{2}\right)^{-1}\left(1+\frac{z^{2}}{\theta-2}\right)^{-.5(\theta+1)}
$$

where $\theta>2$ is the degrees of freedom (controling the tail behavior) and $\Gamma(\cdot)$ is the gamma function. This distribution is normalized to have unit variance and becomes the standard normal distribution when $\theta \rightarrow \infty$. Under a Student's $t$ distribution for the errors, the $\log$ likelihood function takes the form

$$
L=-\frac{T}{2} \log \left(\theta^{-.5} \pi^{-.5} \Gamma\left(\frac{\theta+1}{2}\right) \Gamma\left(\frac{\theta}{2}\right)^{-1}\right)-\frac{1}{2} \sum_{t=1}^{T} \log \sigma_{t}^{2}-\frac{\theta+1}{2} \sum_{t=1}^{T} \log \left[1+\frac{\varepsilon_{t}^{2}}{\sigma_{t}^{2}(\theta-2)}\right] .
$$

The generalized error distribution (GED) is given by

$$
f(z)=\frac{\nu \exp \left[-\frac{1}{2}|z / \lambda|^{\nu}\right]}{\lambda 2^{(1+1 / \nu)} \Gamma(1 / \nu)}
$$

where $-\infty<z<\infty, 0<\nu \leq \infty, \Gamma(\cdot)$ is the gamma function, and

$$
\lambda \equiv\left[\frac{2^{(-2 / \nu)} \Gamma(1 / \nu)}{\Gamma(3 / \nu)}\right]^{1 / 2}
$$

Above, $\nu$ is a tail-thickness parameter, $\nu>0$. When $\nu=2, z$ has a standard normal distribution. For $\nu<2$, the distribution of $z$ has thicker tails than the normal (for example, when $\nu=1, z$ has a double exponential distribution). For $\nu>2$, the distribution of $z$ has thinner tails than the normal (for example, for $\nu=\infty, z$ is uniformly distributed on the interval $\left[-3^{1 / 2}, 3^{1 / 2}\right]$. Under a GED distribution for the errors, the log likelihood function takes the form

$$
L=-\frac{T}{2} \log \left(\frac{\Gamma(1 / \nu)^{3}}{\Gamma(3 / \nu)(\nu / 2)^{2}}\right)-\frac{1}{2} \sum_{t=1}^{T} \log \sigma_{t}^{2}-\sum_{t=1}^{T}\left[\frac{\Gamma(3 / \nu) \varepsilon_{t}^{2}}{\sigma_{t}^{2} \Gamma(1 / \nu)}\right]^{\nu / 2} .
$$


We calculate the SIC value for each estimated model for each exchange rate series under each of the three different distributional assumptions and use it to determine the best overall model. We report the final results in Table 5 for each of the eight exchange rate series. The GED distribution provides the best fit for all exchange rate return series, except for the Australian dollar and the Japanese yen for which the Student's $t$ distribution is selected. According to the $Q(36)$ and $Q^{2}(36)$ statistics, reported in the last two columns of Table 5 , we cannot reject the null hypotheses of no autocorrelation and no nonlinearities in the residuals of these optimally selected models.

Finally, we computed the same set of $p$-values for the standardized residuals of the optimal model for each of the eight currencies and report the results in Table 6 , in the same fashion as those in Table 1. There are more significant frames for all the currencies except for the Brazilian real-Canadian dollar exchange rate. More importantly there were only nine highly significant frames for the auto bicorrelation tests. The nonlinearity in the standardized residuals is mainly in the cross bicorrelation portmanteau tests. These results show that the nonlinearity in the exchange rates is not due to GARCH effects but instead due to the exchange rate trading economics. This result corroborates that of Brooks (1996) who finds that the GARCH model is unable to explain all of the observed nonlinearity in the foreign exchange data.

\section{Conclusion}

In this paper we have used a new method of testing for linear and nonlinear lead/lag relationships between time series, introduced by Brooks and Hinich (1999). The method provides a complement to Granger causality analysis, and is general enough to detect many types of nonlinear dependence between series in their conditional means. The test, based on the concepts of cross-correlation and cross-bicorrelation is used to test for the existence of nonlinearity as well as the episodic nature of the nonlinearity, if any exists. Our results indicate that there exists statistically significant episodic nonlinearity either within each of the exchange rate time series or between pairs or both. We also implemented GARCH and EGARCH models, using a variety of error densities and diagnostic checks, and found that this family of models cannot capture episodic nonlinearity present in the exchange rate data.

The evidence of episodic nonlinearity in exchange rate returns has important implications for forecasting these series. We know how to forecast linear dynamical systems with constant coefficients. We may differ about the best way to deal with trends in the series but the dynamics is modeled by a vector autoregressive model and the model is fit by one of the standard least squares methods. The trend plus dynamical model is then used to produce forecasts. However, although the linear modeling and fitting approach may yield useful forecasts of a nonlinear process, there is no way to know when the linear forecasts are very wrong. Moreover, the usefulness of a linear approach to forecasting an episodic nonlinear 
process is even more questionable than the use of a linear approach to forecasting a stationary nonlinear process. If we can learn how to detect when the foreign exchange rate series become nonlinear then we can use linear methods for making short term forecasting during the linear regimes. There is no known method for forecasting nonlinear processes with non zero bicorrelations and cross bicorrelations. Forecasting of such nonlinear processes is an important and difficult mathematical and statistical problem that should attract more attention than it has received in the time series field. 


\section{References}

[1] Baillie, R.T and T. Bollerslev. "The Message in Daily Exchange Rates: A ConditionalVariance Tale." Journal of Business and Economic Statistics 7 (1989), 297-305.

[2] Bollerslev, T. "Generalized Autoregressive Conditional Heteroscedasticity." Journal of Econometrics 31 (1986), 307-327.

[3] Bollerslev, T. "A Conditional Heteroskedastic Time Series Model for Speculative Prices and Rates of Return." Review of Economics and Statistics 9 (1987), 542-547.

[4] Brooks, C. "Testing for Nonlinearities in Daily Sterling Exchange Rates." Applied Financial Economics 6 (1996), 307-317.

[5] Brooks, C. and M.J. Hinich. "Cross-Correlations and Cross-Bicorrelations in Sterling Exchange Rates." Journal of Empirical Finance 20 (1999), 385-404.

[6] Campbell, J.Y., K.S. Medeiros, and L.M. Viceira. "Global Currency Hedging." NBER Working Paper No. W13088 (2007).

[7] Devereux, M.B. and A. Sutherland. "Financial Globalization and Monetary Policy." IMF Working Paper (2007).

[8] Dickey, D.A., and W.A. Fuller. "Likelihood Ratio Statistics for Autoregressive Time Series with a Unit Root." Econometrica 49 (1981), 1057-72.

[9] Engle, R.F. "Autoregressive Conditional Heteroscedasticity with Estimates of the Variance of United Kingdom Inflation." Econometrica 50 (1982), 987-1007.

[10] Hinich, M.J. "Testing for Dependence in the Input to a Linear Time Series Model." Journal of Nonparametric Statistics 6 (1996), 205-221.

[11] Hsieh, D.A. "Modeling Heteroscedasticity in Daily Foreign-Exchange Rates." Journal of Business and Economic Statistics 7 (1989), 307-317.

[12] Jarque, C.M. and A.K. Bera. "Efficient Tests for Normality, Homoscedasticity, and Serial Independence of Regression Residuals." Economics Letters 6 (1980), 255-259.

[13] Lane, P. and G.M. Milesi-Ferretti. "The External Wealth of Nations: Measures of Foreign Assets and Liabilities for Industrial and Developing Countries." Journal of International Economics 55 (2001), 263-94.

[14] Lane, P. and G.M. Milesi-Ferretti. "The External Wealth of Nations Mark II." IMF Working Paper No 06-69 (2006). 
[15] Ljung, G. and G. Box. "On a Measure of Lack of Fit in Time Series Models." Biometrica 66 (1979), 265-270.

[16] Mandelbrot, B.B. and R.L. Hudson. The (Mis)Behavior of Markets: A Fractal View of Risk, Ruin 83 Reward. New York: Basic Books (2004).

[17] Merton, R.C. "On Estimating the Expected Return on the Market." Journal of Financial Economics 8 (1980), 323-361.

[18] Nelson, D. "Conditional Heteroscedasticity in Asset Returns: A New Approach." Unpublished Ph.D. Dissertation, Department of Economics, Massachusetts Institute of Technology (1988).

[19] Pantula S.G., G. Gonzalez-Farias, and W.A. Fuller. "A Comparison of Unit-Root Test Criteria." Journal of Business and Economic Statistics 12 (1994), 449-459.

[20] Phillips, P.C.B. "Time Series Regresion with a Unit Root." Econometrica 55 (1987), 277-301.

[21] Phillips, P.C.B. and P. Perron. "Testing for a Unit Root in Time Series Regression." Biometrica 75 (1988), 335-346.6), 228-252. 
Figure 1. Daily United States Dollar Prices of Eight Currencies, 2000-2009.

Australian Dollar

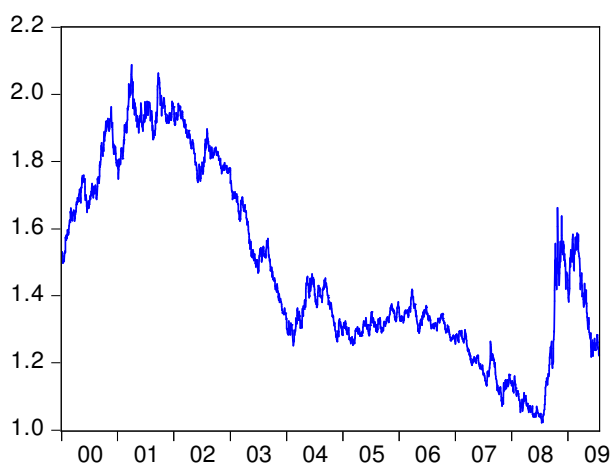

Brazilian Rea

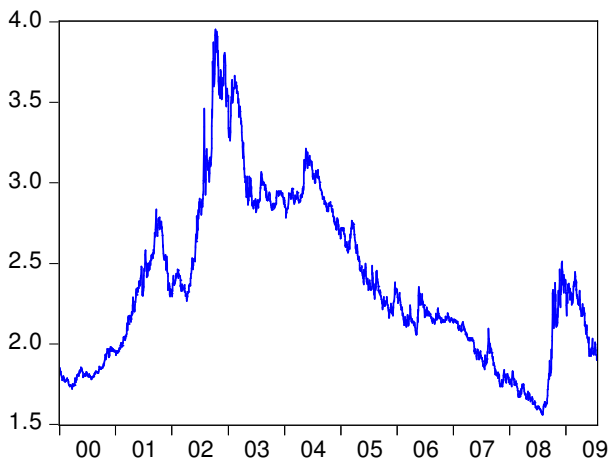

Euro

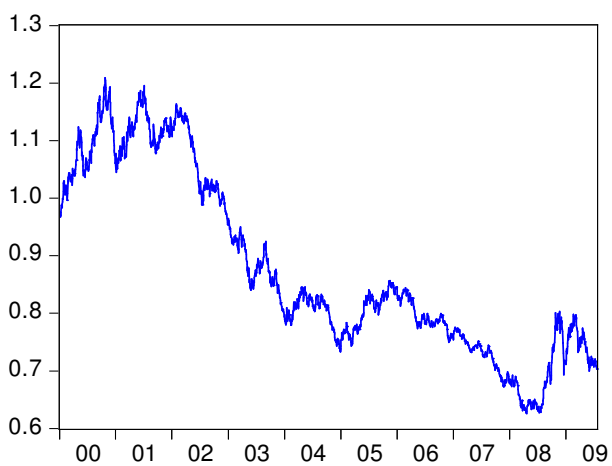

Mexican Peso

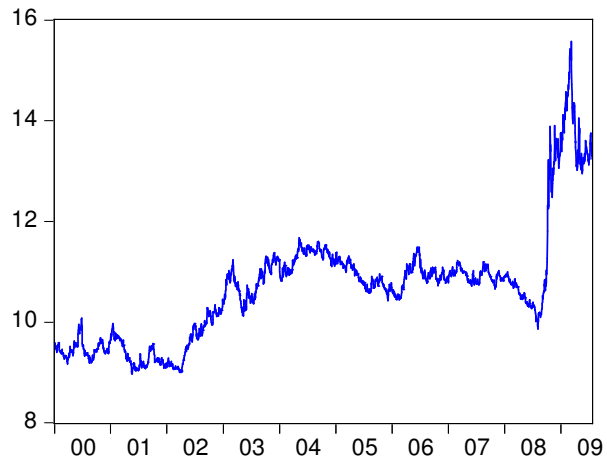

British Pound

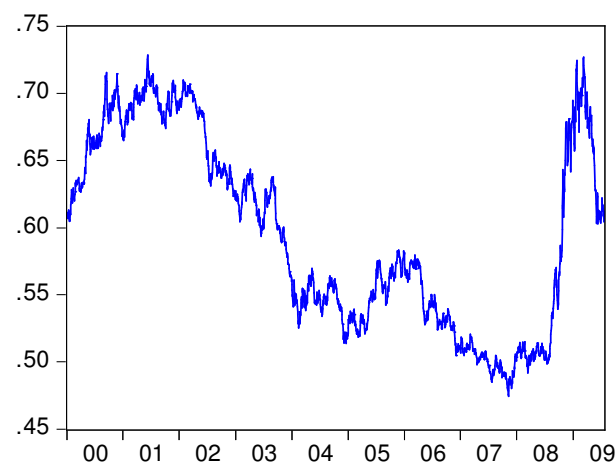

Canadian Dollar

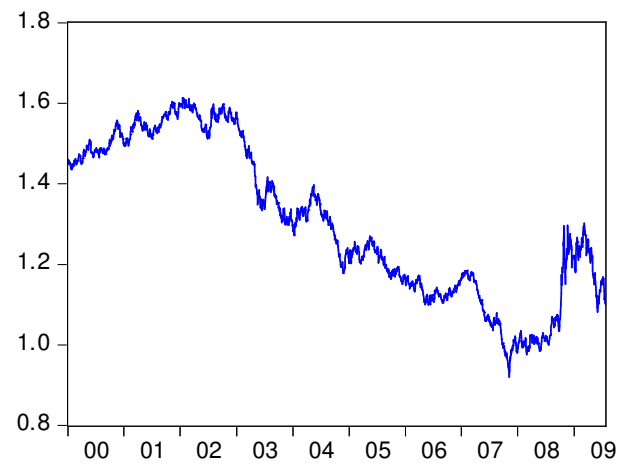

Japanese Yen

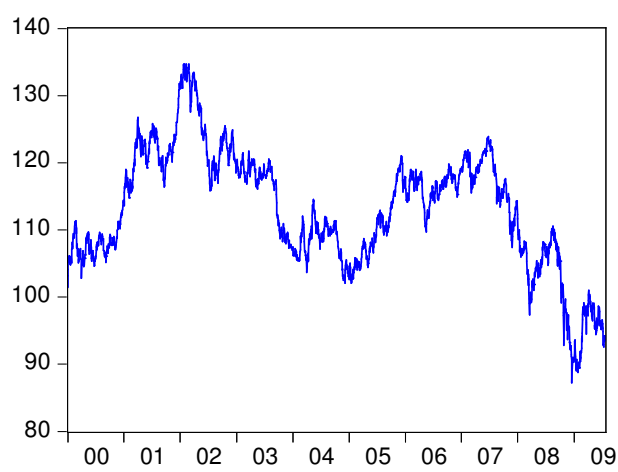

Sw iss Franc

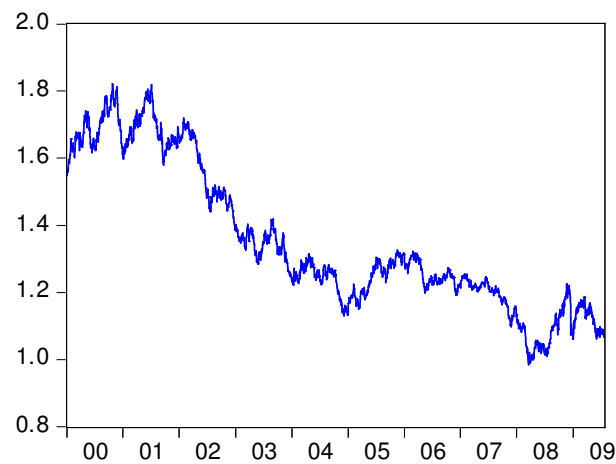


Figure 2. Logged First Differences of the Nominal Exchange Rates

Australian Dollar

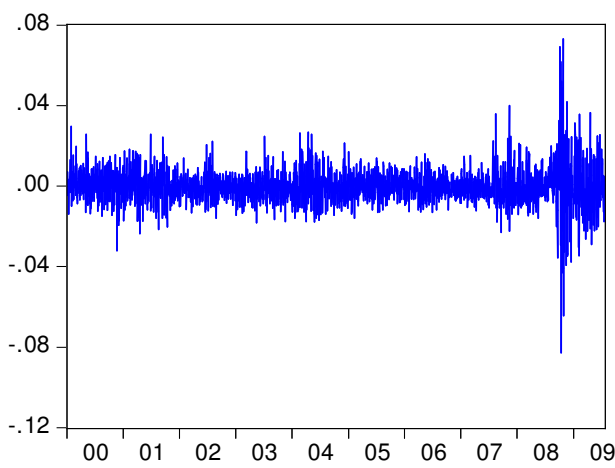

Brazilian Real

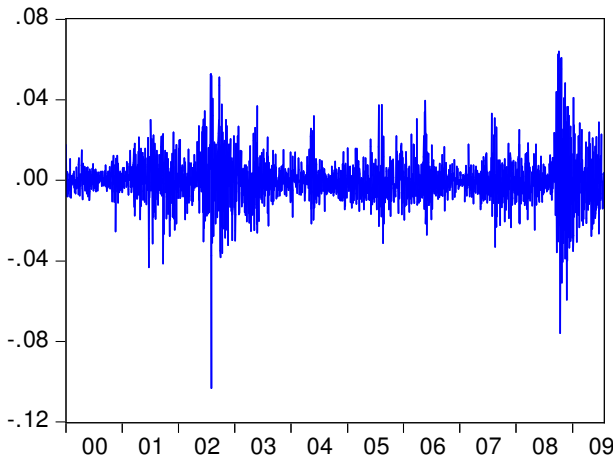

Euro

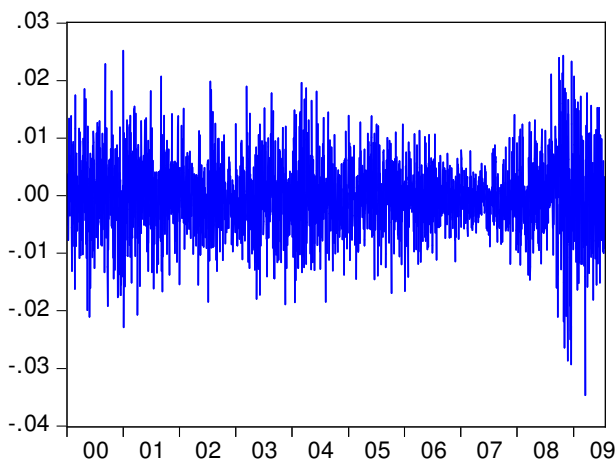

Mexican Peso

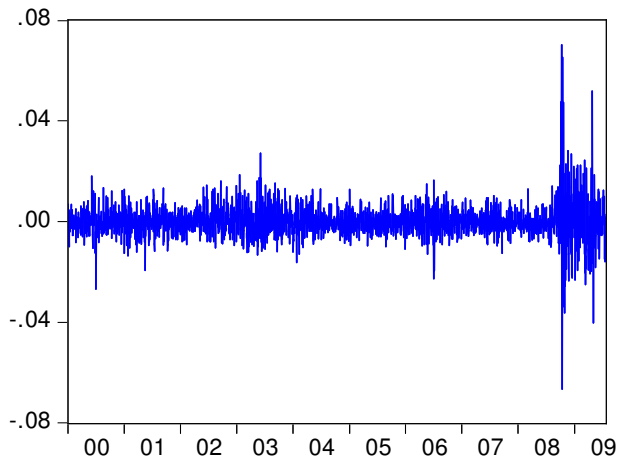

British Pound

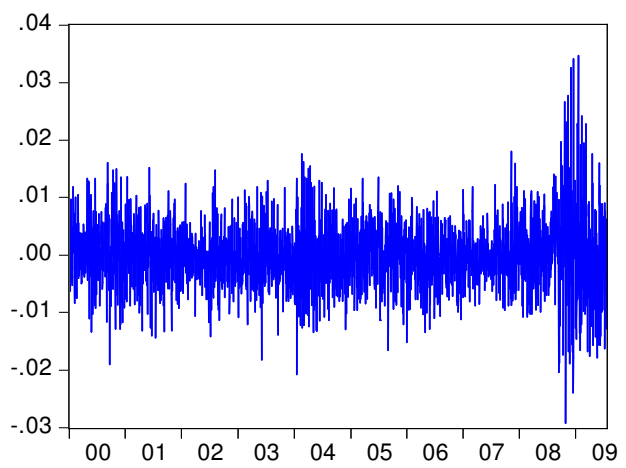

Canadian Dollar

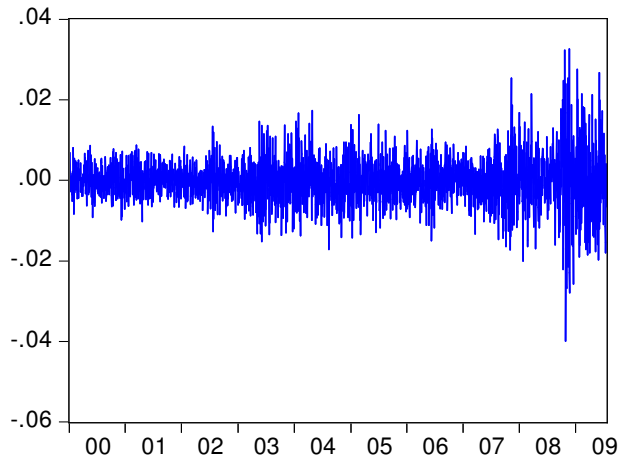

Japanese Yen

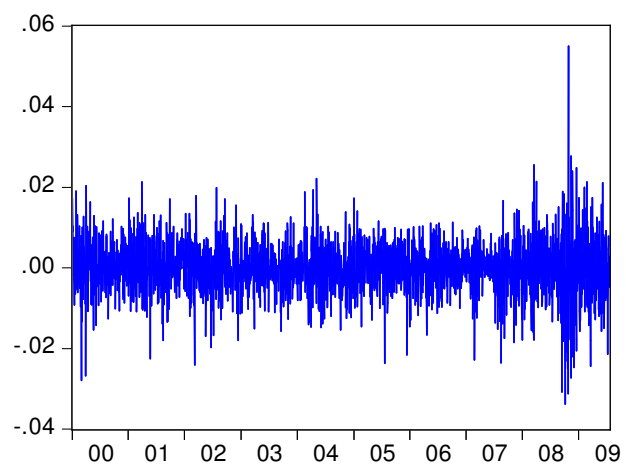

Sw iss Franc

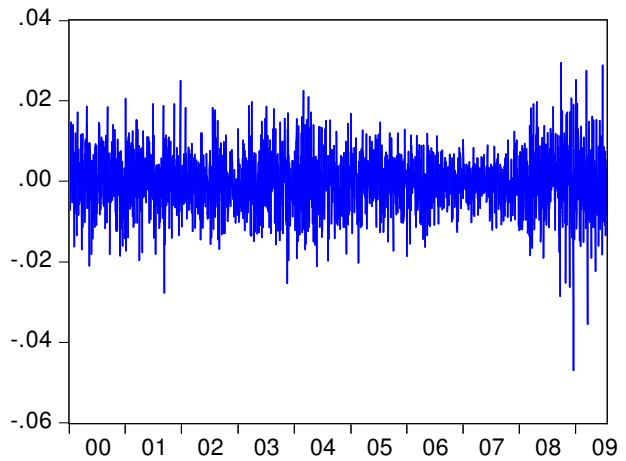


Figure 3. Frequency Distributions of the Logged First Differences of the Nominal Exchange Rates
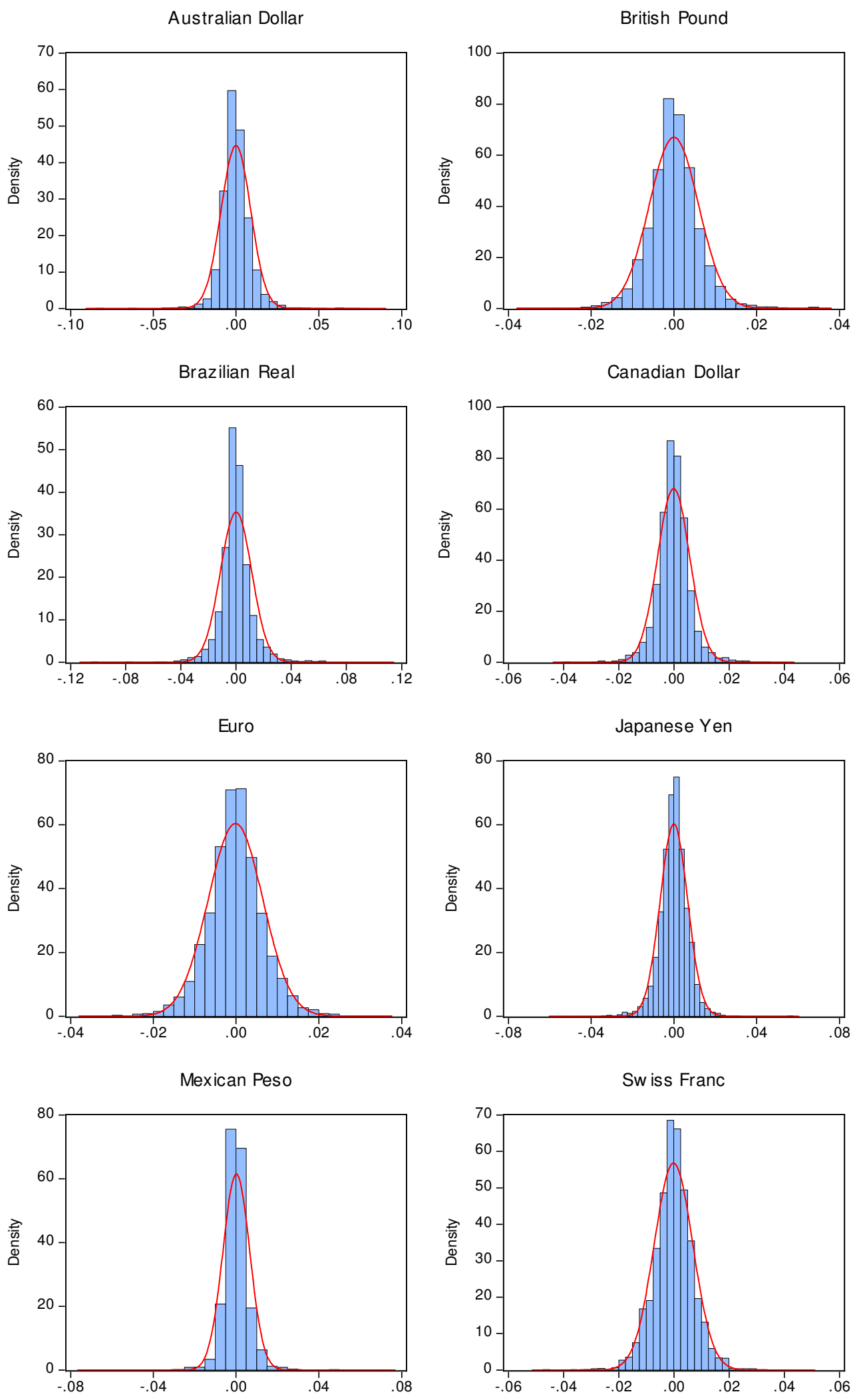

$\square$ Histogram — Normal 


\section{Table 1. Portmanteau Statistics $p$-Values For Exchange Rate Returns}

\begin{tabular}{|c|c|c|c|c|c|}
\hline \multirow[b]{2}{*}{ Exchange rate pairs } & \multirow{2}{*}{$\begin{array}{l}\text { Frame } \\
\text { start day }\end{array}$} & \multicolumn{4}{|c|}{$p$-values } \\
\hline & & $H_{x y y}$ & $H_{x y y}$ & $H_{x y y}$ & $H_{x y y}$ \\
\hline Australian dollar-British pound & $6 / 10 / 2008$ & .0000 & .1582 & .0001 & .0702 \\
\hline \multirow[t]{3}{*}{ British pound-Canadian dolar } & $4 / 23 / 2002$ & & .0000 & & .0133 \\
\hline & $9 / 4 / 2007$ & & .0004 & & \\
\hline & $6 / 10 / 2008$ & & .0032 & & .0026 \\
\hline British pound-Euro & $7 / 17 / 2001$ & & .0083 & & \\
\hline \multirow[t]{7}{*}{ Brazilian real-Canadian dollar } & $4 / 23 / 2002$ & .0000 & .0000 & .0108 & .0101 \\
\hline & $6 / 17 / 2003$ & .0004 & & & \\
\hline & $5 / 17 / 2005$ & .0058 & & & \\
\hline & $2 / 21 / 2006$ & .0018 & & & \\
\hline & $4 / 17 / 2007$ & .0027 & & & \\
\hline & $9 / 4 / 2007$ & & .0004 & & \\
\hline & $6 / 10 / 2008$ & .0000 & .0032 & .0000 & .0000 \\
\hline \multirow[t]{4}{*}{ Canadian dollar-Mexican peso } & $4 / 23 / 2002$ & .0000 & & & \\
\hline & $4 / 17 / 2007$ & & .0016 & & \\
\hline & $9 / 4 / 2007$ & .0004 & .0195 & & .0367 \\
\hline & $6 / 10 / 2008$ & .0032 & .0000 & .0000 & .0000 \\
\hline
\end{tabular}


Table 1 (Continued). Portmanteau Statistics $p$-Values For Exchange Rate Returns

\begin{tabular}{|c|c|c|c|c|c|}
\hline \multirow[b]{2}{*}{ Exchange rate pairs } & \multirow{2}{*}{$\begin{array}{l}\text { Frame } \\
\text { start day }\end{array}$} & \multicolumn{4}{|c|}{$p$-values } \\
\hline & & $H_{x y y}$ & $H_{x y y}$ & $H_{x y y}$ & $H_{x y y}$ \\
\hline \multirow[t]{5}{*}{ Euro-Yen } & $7 / 17 / 2001$ & .0083 & .0115 & & \\
\hline & $12 / 4 / 2001$ & & .0092 & & \\
\hline & $11 / 28 / 2006$ & & .0056 & & \\
\hline & $4 / 17 / 2007$ & & .0014 & & \\
\hline & $1 / 22 / 2008$ & & .0000 & & \\
\hline \multirow[t]{3}{*}{ Euro-Mexican peso } & $7 / 17 / 2001$ & .0083 & & & \\
\hline & $4 / 17 / 2007$ & & .0016 & & \\
\hline & $6 / 10 / 2008$ & & .0000 & & .0000 \\
\hline \multirow[t]{2}{*}{ Australian dollar-euro } & $7 / 17 / 2008$ & .0298 & .0083 & & \\
\hline & $6 / 10 / 2008$ & .0000 & & .0014 & \\
\hline Australian dollar-Swiss franc & $6 / 10 / 2008$ & .0000 & & & \\
\hline \multirow[t]{5}{*}{ British pound-Yen } & $12 / 4 / 2001$ & & .0092 & & \\
\hline & $11 / 28 / 2006$ & & .0056 & & \\
\hline & $4 / 17 / 2007$ & & .0014 & & \\
\hline & $1 / 22 / 2008$ & & .0000 & & \\
\hline & $6 / 10 / 2008$ & & .0147 & .0018 & \\
\hline \multirow[t]{3}{*}{ Canadian dollar-Swiss franc } & $4 / 23 / 2002$ & .0000 & .0144 & .0000 & \\
\hline & $9 / 4 / 2007$ & .0004 & & & \\
\hline & $6 / 10 / 2008$ & .0032 & & & \\
\hline Euro-Swiss franc & $7 / 17 / 2001$ & .0083 & & .0500 & \\
\hline
\end{tabular}


Table 2. Autoregressive Model Lag Selection

\begin{tabular}{|c|c|c|c|c|}
\hline \multirow[b]{2}{*}{ Series } & \multirow{2}{*}{$\begin{array}{l}\text { Min AR } \\
\text { order* }\end{array}$} & \multicolumn{2}{|c|}{$\begin{array}{l}\text { Model overfitting } \\
\text { lag selection }\end{array}$} & \multirow{2}{*}{$\begin{array}{c}\text { AR lag } \\
\text { selection }\end{array}$} \\
\hline & & AIC & $\mathrm{SIC}$ & \\
\hline Australian dollar & 6 & 8 & 6 & 6 \\
\hline British pound & 10 & 10 & 10 & 10 \\
\hline Brazilian real & 16 & 19 & 16 & 16 \\
\hline Canadian dollar & 13 & 13 & 13 & 13 \\
\hline Euro & 1 & 1 & 1 & 1 \\
\hline Japanese yen & 4 & 4 & 4 & 4 \\
\hline Mexican peso & 14 & 19 & 14 & 14 \\
\hline Swiss franc & 1 & 1 & 1 & 1 \\
\hline
\end{tabular}

Table 3. AR Model Serial Correlation Tests

\begin{tabular}{lccc} 
& & \multicolumn{2}{c}{$p$-value } \\
\cline { 3 - 4 } Series & AR lag selection & $Q(36)$ & $Q^{2}(36)$ \\
\hline & & & \\
Australian dollar & 6 & .059 & .000 \\
British pound & 10 & .093 & .000 \\
Brazilian real & 16 & .147 & .000 \\
Canadian dollar & 13 & .166 & .000 \\
Euro & 1 & .496 & .000 \\
Japanese yen & 4 & .110 & .000 \\
Mexican peso & 14 & .054 & .000 \\
Swiss franc & 1 & .288 & .000 \\
\hline
\end{tabular}


Table 4. Conditional Variance Selected Models

\begin{tabular}{lrr} 
Series & AIC & \multicolumn{1}{c}{ SIC } \\
\hline Australian dollar & GARCH $(1,1)$ & GARCH $(1,1)$ \\
British pound & GARCH $(1,1)$ & GARCH $(1,1)$ \\
Brazilian real & EGARCH $(1,1)$ & EGARCH $(1,1)$ \\
Canadian dollar & GARCH $(2,1)$ & GARCH $(1,1)$ \\
Euro & GARCH $(1,2)$ & GARCH $(1,1)$ \\
Japanese yen & GARCH $(1,1)$ & GARCH $(1,1)$ \\
Mexican peso & GARCH $(1,1)$ & GARCH $(1,1)$ \\
Swiss franc & GARCH $(1,1)$ & GARCH $(1,1)$ \\
\hline
\end{tabular}

Table 5. Selection of Best Overall Model

\begin{tabular}{lccccc} 
& & Conditional & & \multicolumn{2}{c}{$p$-value } \\
\cline { 5 - 6 } Series & AR order & variance & Distribution & $Q(36)$ & $Q^{2}(36)$ \\
\hline & & & & & \\
Australian dollar & 6 & GARCH(1,1) & Student's $t$ & .505 & .083 \\
British pound & 10 & GARCH(1,1) & GED & .974 & .446 \\
Brazilian real & 16 & EGARCH(1,1) & GED & .773 & .445 \\
Canadian dollar & 13 & GARCH $(1,1)$ & GED & .994 & .271 \\
Euro & 1 & GARCH $(1,1)$ & GED & .881 & .192 \\
Japanese yen & 4 & GARCH $(1,1)$ & Student's $t$ & .812 & .532 \\
Mexican peso & 14 & GARCH $(1,1)$ & GED & .997 & .224 \\
Swiss franc & 1 & GARCH $(1,1)$ & GED & .634 & .960 \\
\hline
\end{tabular}


Figure 4. Frequency Distributions of Standardized Residuals
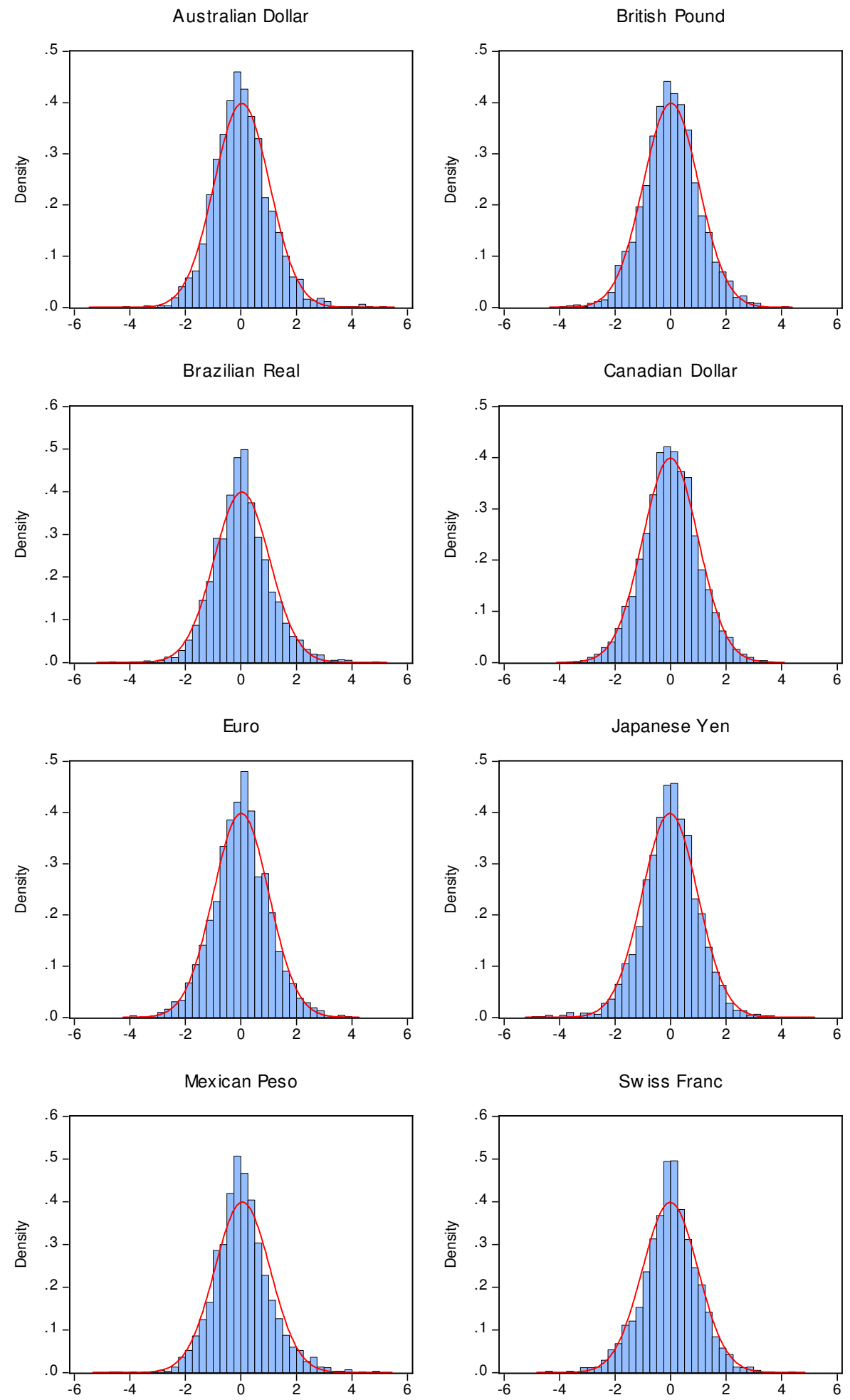

- Normal $\square$ Histogram 
Table 2. Portmanteau Statistics $p$-Values

For The Standardized Residuals

\begin{tabular}{|c|c|c|c|c|c|}
\hline \multirow[b]{2}{*}{ Exchange rate pairs } & \multirow{2}{*}{$\begin{array}{l}\text { Frame } \\
\text { start day }\end{array}$} & \multicolumn{4}{|c|}{$p$-values } \\
\hline & & $H_{x y y}$ & $H_{x y y}$ & $H_{x y y}$ & $H_{x y y}$ \\
\hline \multirow[t]{5}{*}{ Australian dollar-British pound } & $1 / 26 / 2000$ & & & .0040 & \\
\hline & $5 / 15 / 2002$ & & & & .0092 \\
\hline & $11 / 26 / 2003$ & & & .0037 & .0006 \\
\hline & $9 / 26 / 2007$ & & & .0099 & .0000 \\
\hline & $7 / 02 / 2008$ & & & .0000 & .0000 \\
\hline \multirow[t]{3}{*}{ British pound-Canadian dolar } & $5 / 15 / 2002$ & & .0000 & & .0000 \\
\hline & $9 / 26 / 2007$ & & & .0031 & .0009 \\
\hline & $7 / 02 / 2008$ & & & .0000 & .0000 \\
\hline \multirow[t]{5}{*}{ British pound-Euro } & $1 / 26 / 2000$ & & & .0000 & .0012 \\
\hline & $5 / 15 / 2002$ & & & .0001 & .0042 \\
\hline & $2 / 19 / 2003$ & & & .0027 & \\
\hline & $11 / 26 / 2003$ & & & .0009 & .0006 \\
\hline & $7 / 02 / 2008$ & & & .0000 & .0000 \\
\hline \multirow[t]{4}{*}{ Brazilian real-Canadian dollar } & $5 / 15 / 2002$ & & & .0000 & .0000 \\
\hline & $3 / 15 / 2006$ & & & .0016 & .0399 \\
\hline & $5 / 09 / 2007$ & & & .0004 & \\
\hline & $7 / 02 / 2008$ & & & .0000 & .0000 \\
\hline \multirow[t]{4}{*}{ Canadian dollar-Mexican peso } & $5 / 15 / 2002$ & .0000 & & & \\
\hline & $2 / 19 / 2003$ & & & .0052 & .0060 \\
\hline & $9 / 26 / 2007$ & & & .0006 & .0000 \\
\hline & $7 / 02 / 2008$ & & .0142 & .0000 & .0000 \\
\hline \multirow[t]{5}{*}{ Euro-Yen } & $1 / 26 / 2000$ & & & & .0000 \\
\hline & $11 / 01 / 2000$ & & & .0116 & .0066 \\
\hline & $12 / 20 / 2006$ & & & & .0099 \\
\hline & $2 / 13 / 2008$ & & & & .0035 \\
\hline & $7 / 02 / 2008$ & & & .0001 & .0000 \\
\hline \multirow[t]{5}{*}{ Euro-Mexican peso } & $3 / 21 / 2001$ & & & & .0017 \\
\hline & $2 / 19 / 2003$ & & & .0003 & .0000 \\
\hline & $11 / 26 / 2003$ & & .0482 & & .0002 \\
\hline & $3 / 15 / 2006$ & & & & .0080 \\
\hline & $7 / 02 / 2008$ & & & .0000 & .0000 \\
\hline
\end{tabular}


Table 2 (Continued). Portmanteau Statistics $p$-Values

For The Standardized Residuals

\begin{tabular}{|c|c|c|c|c|c|}
\hline \multirow[b]{2}{*}{ Exchange rate pairs } & \multirow{2}{*}{$\begin{array}{l}\text { Frame } \\
\text { start day }\end{array}$} & \multicolumn{4}{|c|}{$p$-values } \\
\hline & & $H_{x y y}$ & $H_{x y y}$ & $H_{x y y}$ & $H_{x y y}$ \\
\hline \multirow[t]{4}{*}{ Australian dollar-Euro } & $1 / 26 / 2000$ & & & .0010 & \\
\hline & $5 / 09 / 2007$ & & & .0001 & \\
\hline & $9 / 26 / 2007$ & & & & .0030 \\
\hline & $7 / 02 / 2008$ & & & .0000 & .0000 \\
\hline \multirow[t]{4}{*}{ Australian dollar-Swiss franc } & $8 / 08 / 2001$ & .0264 & & .0002 & .0005 \\
\hline & $5 / 09 / 2007$ & & & .0034 & \\
\hline & $2 / 13 / 2008$ & & .0460 & .0282 & .0000 \\
\hline & $7 / 02 / 2008$ & & & .0000 & .0000 \\
\hline \multirow[t]{5}{*}{ British pound-Yen } & $7 / 09 / 2003$ & & & & .0041 \\
\hline & $3 / 15 / 2006$ & & & .0067 & \\
\hline & $9 / 26 / 2007$ & & & .0000 & .0083 \\
\hline & $2 / 13 / 2008$ & & & & .0001 \\
\hline & $7 / 02 / 2008$ & & & .0000 & .0000 \\
\hline \multirow[t]{3}{*}{ Canadian dollar-Swiss franc } & $5 / 15 / 2002$ & .0000 & & .0000 & .0011 \\
\hline & $2 / 13 / 2008$ & & .0460 & & .0004 \\
\hline & $7 / 02 / 2008$ & & & .0000 & .0000 \\
\hline \multirow[t]{9}{*}{ Euro-Swiss franc } & $1 / 26 / 2000$ & & & .0000 & .0000 \\
\hline & $11 / 01 / 2000$ & & & .0094 & \\
\hline & $8 / 08 / 2001$ & & & .0000 & .0000 \\
\hline & $5 / 15 / 2002$ & & & .0000 & .0000 \\
\hline & $2 / 19 / 2003$ & & & .0013 & .0123 \\
\hline & $11 / 26 / 2003$ & & & .0043 & .0374 \\
\hline & $2 / 13 / 2008$ & & .0460 & & .0005 \\
\hline & $7 / 02 / 2008$ & & & .0000 & .0000 \\
\hline & $11 / 19 / 2008$ & & & .0001 & .0000 \\
\hline
\end{tabular}

